\title{
Structural equations modelling to quantify the effect of direct and intermediate factors on fertility changes in Egypt during 2000-2014
}

Abdelghany Abdelghany, ${ }^{1}$ Abdelhamid M. El Abbbasy ${ }^{1}$ and Abdelhameed El Shabrawy ${ }^{1}$

${ }^{1}$ Biostatistics and Demography, Institute of Statistical Studies and Research, Cairo University, Cairo, Egypt. (Correspondence to: Abdelhameed El Shabrawy: a.elshabrawy@cu.edu.eg).

\begin{abstract}
Background: Egypt's population increased by 10 million between 2011 and 2014 and the total fertility rate increased to 3.5 births per woman.

Aims: This paper aimed to evaluate the direct and intermediate factors that could explain this increase in the total fertility rate.

Methods: Data from the 2000 and 2014 Egypt Demographic and Health Surveys were used. The average number of births per woman in the 3 years before the survey was used as a proxy for total fertility rate. A structural equations model was used to measure the total effect of direct and intermediate variables on number of births per woman.

Results: The effect of the intermediate variables on births per woman was stronger than the direct factors in both health surveys. In the 2000 and 2014 surveys, the intermediate factors with the greatest effect were: unmet need for family planning methods, discontinuation of using family planning methods in the 5 years before the survey, number of discontinuations of using family planning methods in the 3 years before the survey and child death under 5 years. In the 2000 survey, the direct factors affecting a decline in births per woman were: exposure to family planning messages, woman's work status, wealth index and woman's age 3 years before the survey. In the 2014 health survey, the effect of these variables on fertility declined. This decrease contributed to increasing the total fertility rate to 3.5 births per woman.

Conclusion: Population policies should reintensify efforts to reduce the fertility rate based on the factors that influence fertility, such as family planning messages.

Keywords: birth rate, fertility, family planning, Egypt

Citation: Abdelghany A; El Abbbasy A; El Shabrawy A. Structural equations modelling to quantify the effect of direct and intermediate factors on fertility changes in Egypt during 2000-2014. East Mediterr Health J. 2020;26(10):1210-1217. https://doi.org/10.26719/emhj.20.098

Received: 02/12/18; accepted: 31/07/19

Copyright (C) World Health Organization (WHO) 2020. Open Access. Some rights reserved. This work is available under the CC BY-NC-SA 3.o IGO license (https://creativecommons.org/licenses/by-nc-sa/3.o/igo)
\end{abstract}

\section{Introduction}

The population of Egypt increased greatly during the second half of the 2oth century. This increase has continued in the past two decades. According to census results, the population reached 61.5 million in 1996 with a growth rate of $2.08 \%$ and went up to 94.8 million in 2017 . In addition, the population increased by 10 million in less than 4 years after the revolution of 25th January 2011 (1). Moreover, the report of the 2014 Egypt Demographic and Health Survey (EDHS) indicated that the demand for family planning services had declined substantially (2). The decline in demand for family planning services and the political and economic conditions in Egypt after the revolution contributed to the increase in the total fertility rate (3). An obvious sign of that increase is the rise in the annual number of births from 1850000 in 2006 to 2600200 in 2016 (4), a growth of $40.6 \%$.

Successive EDHS reports show a fluctuation in the total fertility rate; after a series of declines, the total fertility rate reached 3.5 births per woman in 2000 (5). In 2005 , the total fertility rate declined to 3.1 births per woman and then decreased slightly in 2008 to 3.0 births per woman $(6,7)$. The EDHS 2014 revealed an increase in the total fertility rate to 3.5 births per woman, the same as in 2000 (2). Much research has been done on the determinants of fertility at international or national levels. Most of this research indicates that a group of main determinants affects fertility (8-11). Previous studies have examined fertility from different perspectives. Several studies considered the different concepts of fertility and population growth using successive census data and the development of reproductive and fertility measures in urban and rural areas (12,10). Other studies examined the relationship between fertility and different socioeconomic and demographic characteristics and their impact on population growth (13-16). Many studies also suggested different models to explain the effect of direct and indirect factors on fertility (17-19).

In Egypt, research on fertility, population growth and family planning began in the early 1960 s and continues until now. This research suggests that levels of and trends in fertility are affected by determinants such as woman's age at first marriage, discontinuation of using family planning methods and unmet need for family planning methods $(20-23)$. The effect of these determinants varies according to women's characteristics.

In this study, we aimed to identify the determinants of the fertility change in Egypt as a means to interpret the 
change in the total fertility rate during the period 20002014. To achieve this objective, we had two intermediate goals. First, to find a proxy for the total fertility rate. Since the total fertility rate cannot usually be obtained at the micro level (individual woman), we needed to find a suitable proxy for it. We proposed to use the average number of births per woman in the 3 years before the 2000 and 2014 EDHS surveys as a proxy. We show that the change in the total fertility rate and the average births per woman in the 3 years before the survey are very similar in direction and magnitude such that the average births per woman in the 3 years before the survey can be used as a proxy for the total fertility rate at the micro level. Second, to identify the direct and intermediate (between the exogenous variables and the dependent variable) factors affecting the change in births per woman in the 3 years before the survey in Egypt during the period 2000-2014.

\section{Methods}

\section{Study design}

This was a cross-sectional study of the characteristics and determinants of women's fertility and behaviour in Egypt.

Our analysis is based on data from EDHS 2000 and EDHS $2014(2,5)$. The sample designs of the two surveys provide information on various population and health indicators of interest for the country as a whole and for six major subdivisions. Both EDHS 2000 and EDHS 2014 used a multistage sample design. The number of eligible women in EDHS 2000 and EDHS 2014 were 15573 and 21762 , respectively.

\section{Analyses}

We used a correlation analysis to examine the correlation between the values of the total fertility rate and the average number of births per woman in the 3 years before the surveys for the period 1995-2014.

We built a structural equations model to assess the effect of change in fertility determinants on births per woman in the 3 years before the survey based on EDHS 2000 and EDHS 2014. Structural equation modelling is a technique used to describe relationships between variables (24). Using a structural equations model helps to measure the direct, indirect, and total effect of exogenous (independent) and endogenous (intermediate and dependent) variables on an outcome variable. The most powerful feature of a structural equations model is that it can measure the indirect effect that may exist through some endogenous variables, which are called mediator variables. When we are interested in examining the mediation relationships, a structural equations model is more effective than traditional regression models which measure direct effects only. We used AMOS software, version 23, which is a special module of SPSS used only for running a structural equations model and confirmatory factor analysis (25). To build and test our structural equations model, we also used the hot deck imputation method in STATA, version 13 to impute missing data that exist in the variable: gap between ideal number of children and children ever born $(26,27)$.

The acceptability of using a structural equations model rather than a traditional regression model can be seen if we consider, for example, the exogenous variable: exposure to family planning messages. If we use a traditional (linear) regression model to test the effect of this variable on the change in the average births per woman in the 3 years before the survey, only the direct effect can be measured. In the structural equations model, the direct and indirect effect of exposure to family planning messages can be measured. The reason is that this variable affects factors associated with family planning methods (endogenous variables), which also affect the average births per woman in the 3 years before the survey. By considering both direct and indirect effects, we obtain the total effect of exposure to family planning messages on the average births per woman in the 3 years before the survey.

\section{Results}

\section{Change in average births per woman as a proxy for total fertility rate 1995-2014}

The total fertility rate is calculated in EDHS at the macro level; that is, for the whole country and by region and governorate. However, advanced statistical analysis usually requires a large number of observations; we therefore need to use a representative of the total fertility rate at the micro level (individual woman). Based on our results, we propose the use of the average births per woman in the 3 years before the survey as a proxy for the total fertility rate.

We examined the change in both the average births per woman in the 3 years before the survey and the total fertility rate in the series of EDHS during the period 1995$2014(2,5-7,28)$. Data from EDHS 1988 and EDHS 1992 were not included because ever-married women were not asked about the number of births in the 3 years before the survey. Because of space limitations, we compared the direction and magnitude of the total fertility rate and the average births per woman in the 3 years before the survey at the national level only as an example. Figure 1 shows the direction of the average number of births per woman and the total fertility rate during the period 1995-2014 at the national level. The figure shows a similar pattern of change in the direction and magnitude between the total fertility rate and the average births per woman. The proportion of the average number births per woman to the total fertility rate was constant for all years at 0.13 . This finding is a strong indication of the constant change in the two variables throughout the studied period. The same direction and the magnitude between the total fertility rate and the average births per woman were observed in different areas of Egypt (data not shown for space constraints).

In addition, we studied the correlation between the total fertility rate and the average births per woman by 


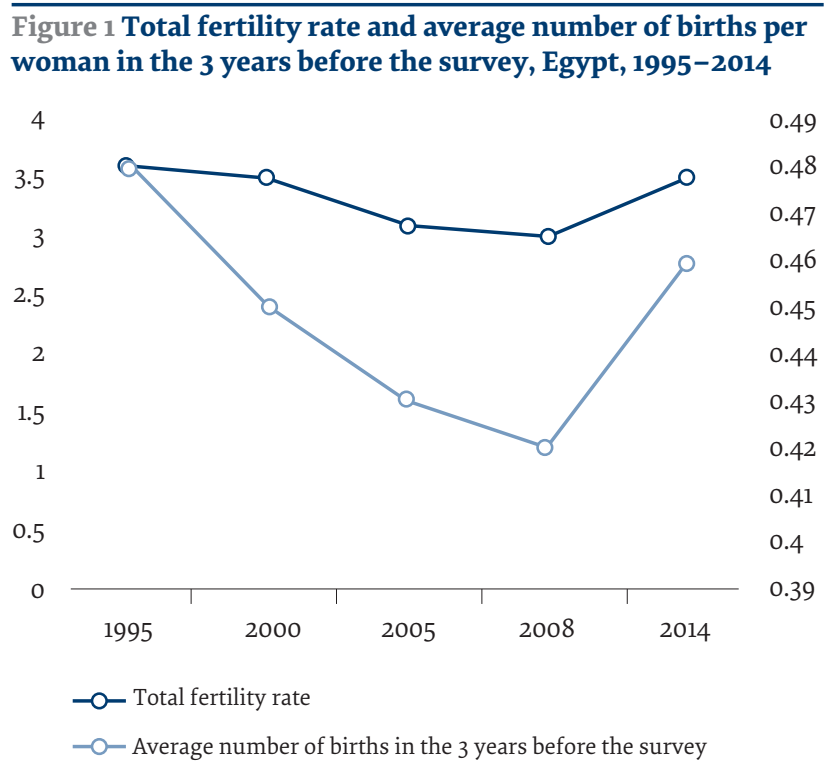

constructing a proximity matrix. A proximity matrix is based on 60 values of total fertility rate and average births per woman (six values for each region) and indicated a high correlation coefficient (0.95) between the total fertility rate and the average births per woman $(P<0.01)$. As a result, the use of the average number of births per woman in the 3 years before the survey as a proxy for the total fertility rate at the micro level is justified.

\section{Exogenous and endogenous variables on births per woman}

We examined different determinants of fertility and their effects on births per woman in the 3 years before the survey in 2000 and 2014. Figure 2 presents a conceptual framework for studying the factors affecting births per woman in the 3 years before the survey. The framework suggests that socioeconomic factors, demographic factors and exposure to family planning messages have a direct effect on births per woman in the 3 years before the survey. Moreover, the framework also suggests that place of residence and socioeconomic factors have an effect on exposure to family planning messages, while exposure to family planning messages affects the endogenous (intermediate) variables related to family planning methods. In addition, the exogenous variables may indirectly affect births per woman in the 3 years before the survey by affecting intermediate factors, which in turn affect births per woman in the 3 years before the survey. A structural equations model was built based on this conceptual framework. Table 1 shows the variables included in our structural equations model. Figure 3 (available on line at: ) illustrates the structure of the structural equations model that was applied to the data of EDHS 2000 and EDHS 2014.

The goodness of fit of our structural equations model was evaluated with a set of indicators and measures and the results are shown in Table 2. The minimum discrepancy index (minimum discrepancy divided by its degrees of freedom) was 3.107, which is less than 5 and therefore in the acceptable range $(29,30)$. The root mean square residual, which is an indicator of the model goodness of fit, was 0.018 , indicating a good fit. The goodness of fit index was 1 indicating an acceptable level of goodness of fit because it exceeds the cut-off value of 0.9 (31). The adjusted goodness of fit index is an alternative to the goodness of fit index, where the value of the index is adjusted according to the number of parameters of the model. The adjusted goodness of fit index was 0.997 which is acceptable (32). The comparative fit index was 0.999 which is an acceptable level of goodness of fit because its value exceeds 0.9 (33). The normed fit index was 0.999 indicating goodness of fit of the model since it exceeds the cut-off value of 0.9 (34). The parsimony ratio index was $17 \%$, which is the ratio of the number of paths dropped according to the model to the number of paths that can be dropped (all paths) (34). Finally, the root mean square error of approximation was 0.008 , which indicates an acceptable level of goodness of fit because it is less than the cut-off value of 0.05 (35).

\section{Effects of exogenous variables on births per woman}

Usually, a structural equations model helps identify the direct, indirect and total effects of exogenous and endogenous variables. We present the total effects only. Table 3 shows values and directions of the total effects of the exogenous (independent) variables on the births per woman in the 3 years before the survey. The total effects of woman's age 3 years before the survey, absolute difference between the ages of the woman and her husband, woman's working status and wealth index were negative in both 2000 and 2014. This means that one unit increase in the variable results in a decrease in the number of births per woman in the 3 years before the survey. For example, the total effect of the woman's age 3 years before the survey was -0.032 in the 2000 model and -0.033 in the 2014 model. This means that when the woman's age increases by 1 year, the number of births per woman in the 3 years before the survey decreases by 32 and 33 births per 1000 women in the 2000 and the 2014 models, respectively.

The total effect of the absolute difference between husband and wife education was positive but small: 0.003 and 0.001 in the 2000 and the 2014 models, respectively. This meant that when the absolute difference in education increased by 1 year, the number of births per woman in the 3 years before the survey increased by three and one births per 1000 women in 2000 and 2014, respectively.

The total effect of place of residence in the 2000 model was positive (0.026), indicating an increase in births per woman in the 3 years before the survey of 26 births per 1000 women when a woman moves from urban to rural residence. However, in the 2014 model, the value of the total effect was negative but small (-0.002).

The magnitude and direction of the total effect of exposure to family planning messages differed between 
Figure 2 Conceptual framework for direct and intermediate factors affecting the number of births per woman in the 3 years before the survey

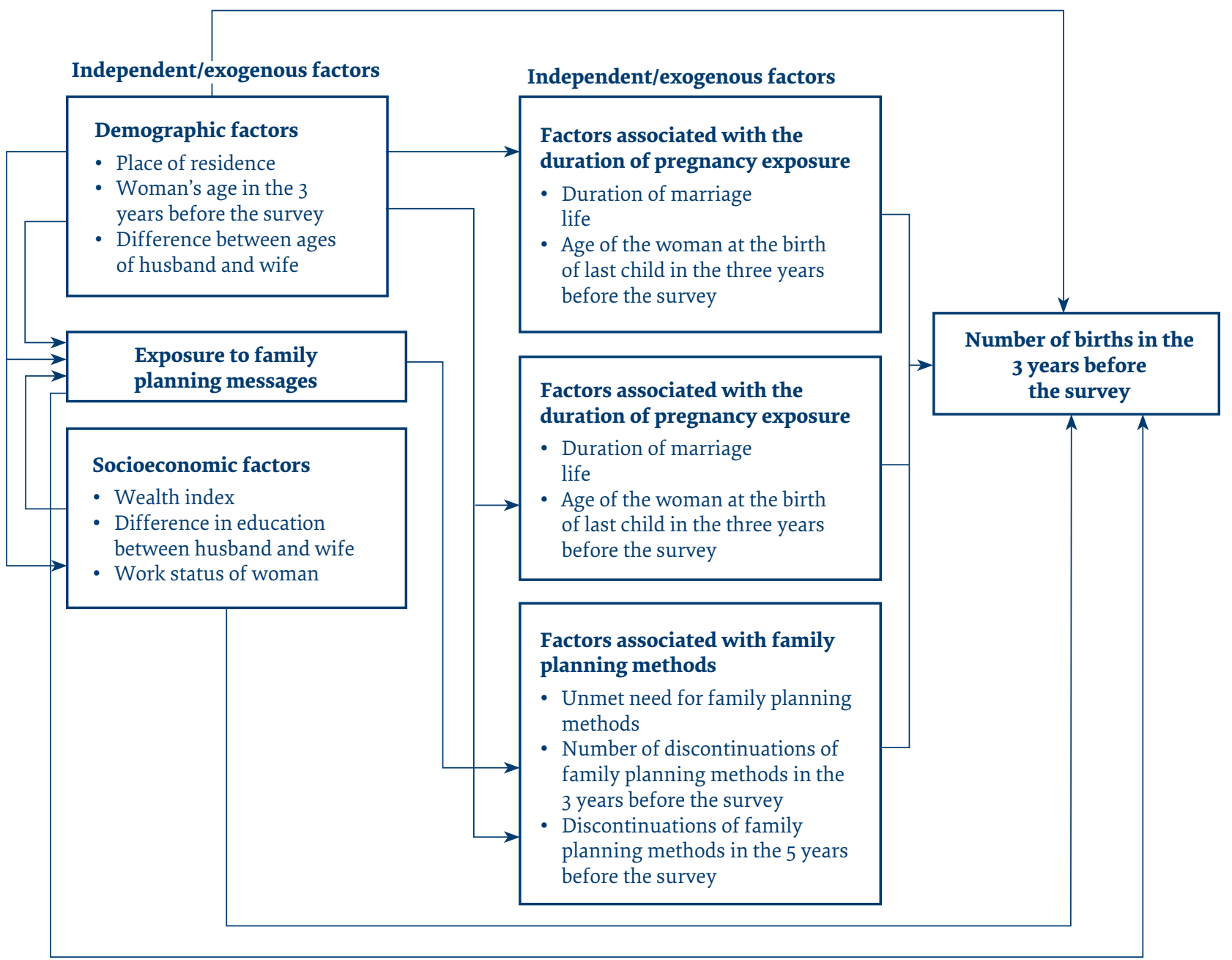

the 2000 and 2014 models. It was negative in the 2000 model (-0.092) and positive in the 2014 model (0.027). Thus, in 2000, exposure to family planning messages resulted in a decrease in births per woman in the 3 years before the survey of 92 births per 1000 women. In contrast in 2014, exposure to family planning messages resulted in an increase in births per woman in the 3 years before the survey of 27 births per 1000 women.

The results shown in Table 3 indicted that the total effect of exogenous variables on births per woman in the 3 years before the survey in the 2000 model was generally weak and even weaker in the 2014 model.

\section{Effects of endogenous variables on births per woman}

Table 4 shows total effects of the endogenous (intermediate) variables on number of births per woman in the 3 years before the survey. Duration of married life had a negative total effect in both $2000(-0.023)$ and 2014 $(-0.014)$ models. This means that a 1-year increase in duration of married life resulted in a decrease in the number of births per woman in the 3 years before the survey of 23 and 14 births per 1000 women in the 2000 and the 2014 models, respectively.

The total effect of woman's age at her last birth before the 3 years preceding the survey in the 2000 model was negative (-0.002), while it is positive in the 2014 model (0.001). However, this effect was weak in both models.

The total effect of all the other endogenous variable was positive. For example, the total effect of unmet need for family planning methods was 0.196 and 0.161 in the 2000 and the 2014 models respectively. Therefore, having an unmet need for family planning methods resulted in an increase in births per woman in the 3 years before the survey of 196 births per 1000 women in the 2000 model and 161 births per 1000 women in the 2014 model.

The total effect of the number of discontinuations of using family planning methods in the 3 years before the survey was 0.06 and 0.157 in the 2000 and 2014 models, respectively. This, when the number of discontinuations of using family planning methods increases by one, the births per woman in the 3 years before the survey 


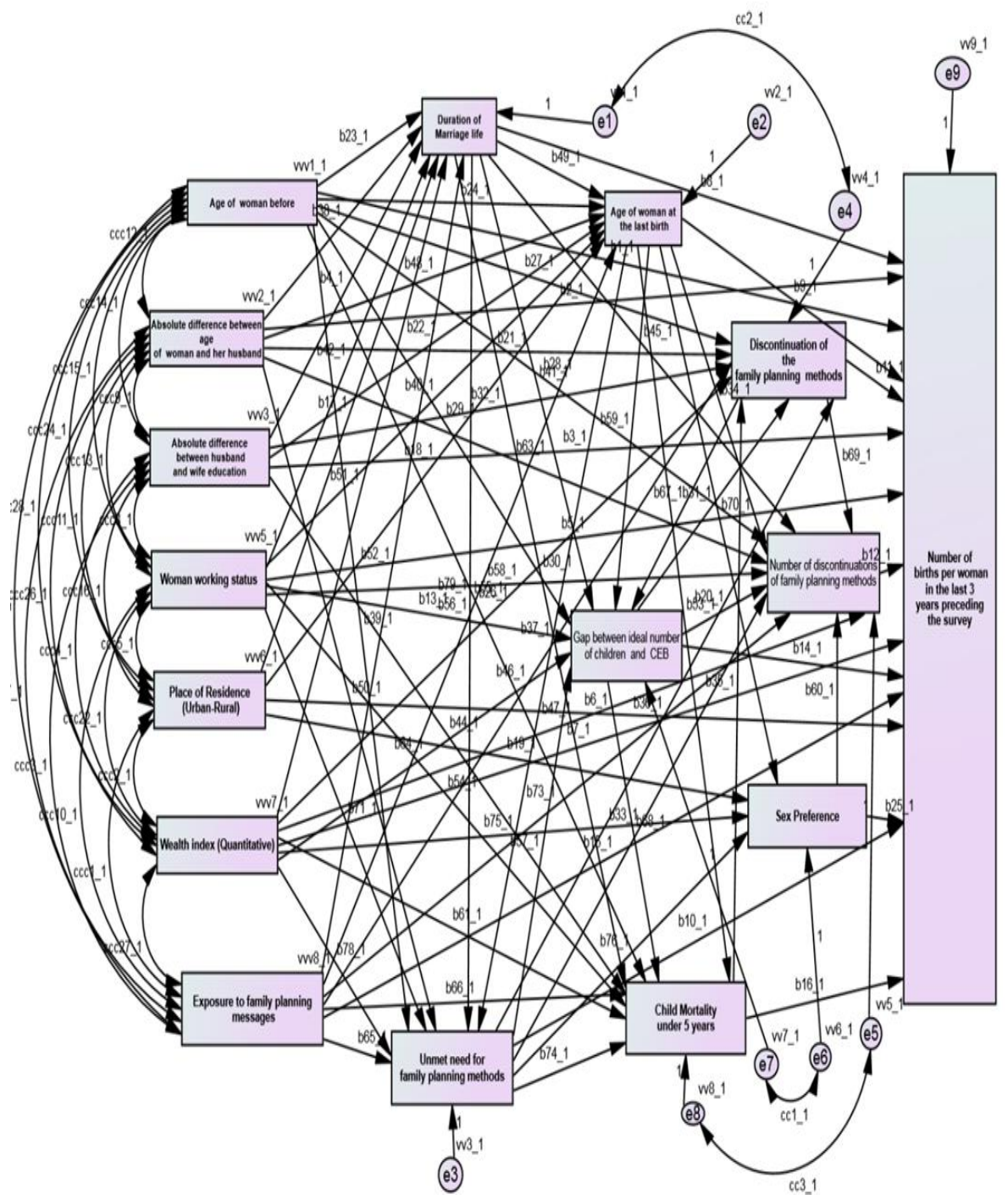

increases by 60 births per 1000 women in the 2000 model and by 157 births per 1000 women in the 2014 model.

The total effect of child death under 5 years was 0.177 and 0.153 in the 2000 and 2014 models, respectively. Thus, one child death under 5 years increased the births per woman in the 3 years before the survey by 177 births per 1000 women in the 2000 model and 153 births per 1000 women in the 2014 model.

By comparing the total effects of the exogenous variables with those of the endogenous variables on births per woman in the 3 years before the survey, we conclude that the increase in the average births per woman in the 3 years before the survey, and hence the total fertility rate, between 2000 and 2014 can be attributed to the intermediate variables.

\section{Discussion}

Our results show that the exogenous variables with the highest total effect on births per woman in the 3 years before the survey in the 2000 model were exposure to family planning messages, woman's work status, wealth index and age of woman 3 years before the survey. The effect of these exogenous variables on births per woman in the 3 years before the survey decreased in the 2014 model. A possible reason for this decline could be, for example, the decline in the total effect of exposure to family planning messages because current media channels pays less attention to spreading awareness of the importance of family planning methods compared with media channels in 2000 when the negative consequences of population growth were widely discussed.

The decline of the total effect of these exogenous variables on births per woman in the 3 years before the survey between the 2000 and 2014 models is a possible reason for the increase in the average births per woman in the 3 years before the survey, and hence the total fertility rate in 2014 which increased to the 2000 rate $(3.5$ births per woman).

Surprisingly, the total effects of the endogenous (intermediate) variables on births per woman in the 3 years before the survey were greater than the total 
effects of the exogenous variables. Moreover, the same intermediate variables affected births per woman in the 3 years before the survey in both the 2000 and the 2014 models, but to different degrees. In the 2000 model, the important variables were the unmet need for family planning methods, discontinuation of using family planning methods in the 5 years preceding the survey, the number of discontinuations of using family planning methods in the 3 years before the survey, and child death under 5 years. In contrast, in the 2014 model, the order was as follows: discontinuation of using family planning methods in the 5 years preceding the survey, unmet need for family planning methods, number of discontinuations of using family planning methods in the 3 years before the survey, and child death under 5 years.

We focused on fertility determinants of women in Egypt during the period 2000 to 2014 only in the 3 years preceding the EDHS surveys. We studied the changes in the average number of births per woman in the 3 years before the survey as a proxy for total fertility rate as the calculation of the total fertility rate in EDHS depends on births per woman in the 3 years before the survey. We did not consider the whole reproductive life of women, such as total number of ever born children or total number of ever born children in women aged 45-49 years.

Our findings highlight the role of the media in raising awareness of reducing the level of fertility. Population policies should reintensify audio and visual family planning messages and make use of modern media channels such as social media networks. In addition, women working is one of the factors that can bring about a reduction in fertility. Consequently, women need to be more enabled to engage in the labour market. Improving the standard of living of households will also contribute to reduced fertility. Hence, efforts should be directed to raising the standard of living. Our results indicate the need to study the factors that reduce the discontinuation of using family planning methods as this factor was an important determinant of average births per woman in the 3 years before the survey. Finally, it is very important to make all family planning methods available and affordable and to provide access to mother and childcare services to reduce unintended births and the level of fertility.

Funding: None.

Competing interests: None declared.

\section{Modélisation d'équations structurelles afin de quantifier l'effet des facteurs directs et intermédiaires de l'évolution de la fécondité en Égypte, de 2000 à 2014 \\ Résumé}

Contexte : La population égyptienne a augmenté de 10 millions de personnes entre 2011 et 2014, tout comme le taux de fécondité total qui est passé à 3,5 naissances par femme.

Objectifs : Le présent article visait à évaluer les facteurs directs et intermédiaires pouvant expliquer cette augmentation du taux de fécondité total.

Méthodes : Nous avons utilisé les données issues des Enquêtes démographiques et sanitaires d'Égypte pour 2000 et 2014. Le nombre moyen de naissances par femme au cours des trois années précédant l'enquête a été employé comme indicateur indirect du taux de fécondité total. Un modèle d'équations structurelles a servi à mesurer l'effet global des variables directes et intermédiaires sur le nombre de naissances par femme.

Résultats : Dans les deux enquêtes, l'effet des variables intermédiaires sur le nombre de naissances par femme était plus fort que celui des facteurs directs. Dans les enquêtes de 2000 et 2014, les facteurs intermédiaires ayant l'effet le plus fort étaient le besoin non satisfait de méthode de planification familiale, l'utilisation discontinue de ces méthodes de planification familiale au cours des cinq années précédant l'enquête, le nombre d'interruptions d'utilisation de méthodes de planification familiale au cours des trois années précédant l'enquête et la mortalité des enfants de moins de cinq ans. Dans l'enquête de 2000, les facteurs directs ayant pour impact un déclin du nombre de naissances par femme étaient les suivant : l'exposition à des méthodes de planification familiale, le statut professionnel de la femme, l'indice de richesse et l'âge de la femme trois ans avant l'enquête. Dans l'enquête de 2014, les effets de ces variables sur la fécondité ont décliné, contribuant ainsi à la croissance du taux de fécondité total, qui a atteint 3,5 naissances par femme.

Conclusions : Les politiques démographiques doivent ré-intensifier les efforts afin de réduire le taux de fécondité sur la base des facteurs impactant la fécondité, tels que les méthodes de planification familiale. 


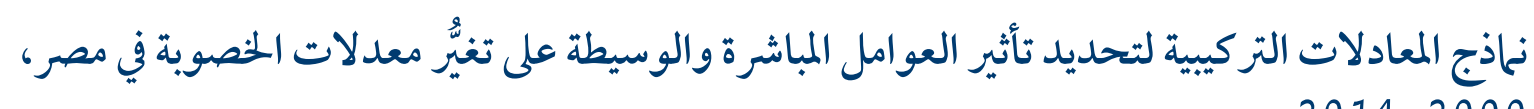

2014-2000

$$
\text { عبد الغني عبد الغني، عبد الحميد العباسي، عبد الحميد الشبراوي }
$$

الخلفية: زاد عدد السكان في مصر بمقدار 10 ملايين نسمة بين عامَيْ 2011 و 2014، وارتفع معدل الخصوبة الكّلّ إلى 3.5 ولادات لكل امرأة. الأهداف: هدفت هذه الدراسة إلى تقييم العو امل المباشرة والوسيطة التي يمكن أن تُفسّر هذه الزيادة في معدل الخصوبة الكُّل.

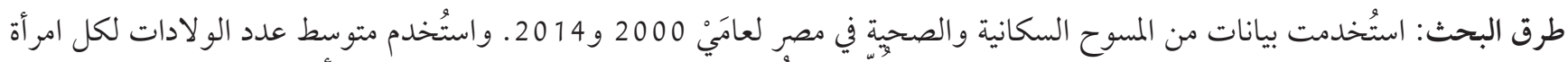

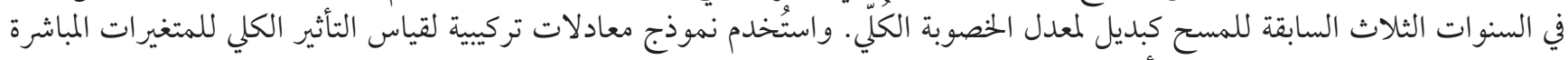

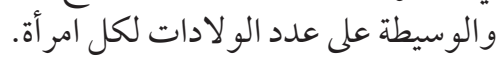

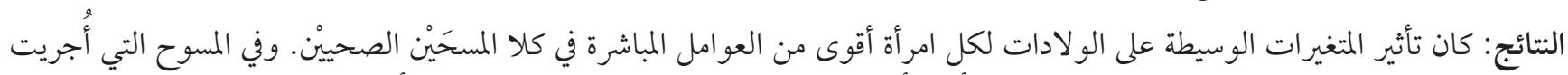

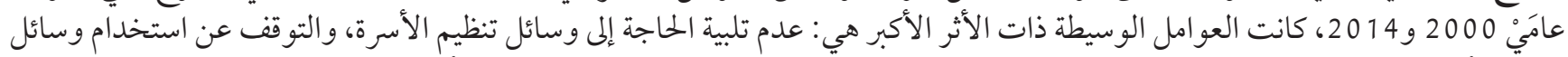

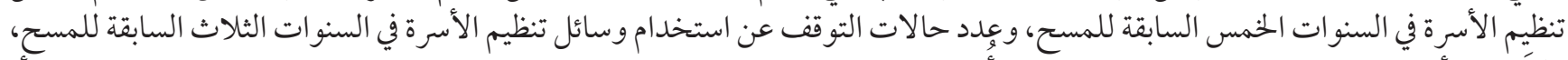

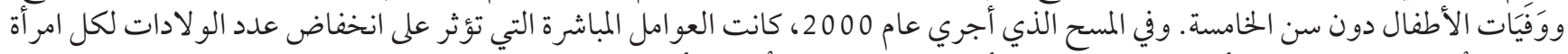

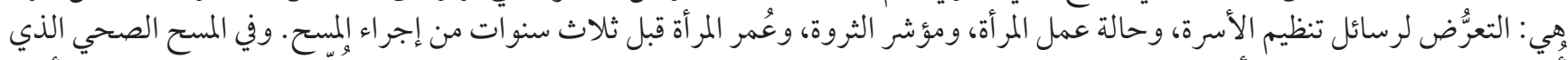

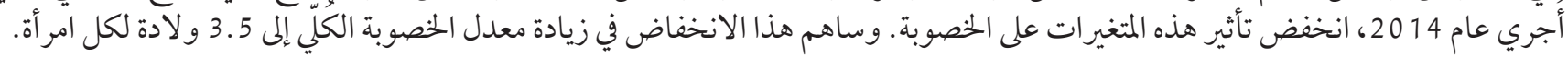
الاستنتاجات: ينبغي للسياسات السكانية أن تعيد تكثيف الجههود الر امية إلى خفض معدل الخصوبة استناداً إلى العوامل التي تؤثّر على الخصوبة، مثل رسائل تنظيم الأسرة.

\section{References}

1. Egypt Census 2017. Cairo: Central Agency for Public Mobilization and Statistics; 2018 (http://www.capmas.gov.eg/Pages/Publicaє tions.aspx?page_id=7195\&Year=23354, accessed 5 March 2020).

2. Ministry of Health and Population [Egypt], El-Zanaty and Associates [Egypt], and ICF International. Egypt Demographic and Health Survey 2014 .Cairo and Rockville (MD): Ministry of Health and Population and ICF International; 2015.

3. Radovich E, El-Shitany A, Sholkamy H, Benova L. Rising up: fertility trends in Egypt before and after the revolution. PloS One. 2018; 13(1):1-14. https://doi.org/10.1371/journal.pone.0190148

4. Rate of natural increase. Cairo: Central Agency for Public Mobilization and Statistics; 2018 (http://www.capmas.gov.eg/Pages/ IndicatorsPage.aspx?Ind_id=1093, accessed 5 March 2020).

5. El-Zanaty F, Way AA. Egypt Demographic and Health Survey 2000. Calverton (MD): Ministry of Health and Population [Arab Republic of Egypt], National population Council [Arab Republic of Egypt], and ORC Macro; 2001.

6. El-Zanaty F, Way AA. Egypt Demographic and Health Survey 2005. Cairo: Ministry of Health and Population, National Population Council, El-Zanaty and Associates, and ORC Macro; 2006.

7. El-Zanaty F, Way A. Egypt Demographic and Health Survey 2008 .Cairo: Ministry of Health and Population, El-Zanaty and Associates, and Macro International; 2009.

8. Yousef A. Providing a Mechanism for Monitoring and Evaluation of Performance of the National Population Program in Egypt. Egypt: Cairo University; 2015.

9. Attari M, Pervaiz Z, Chaudhary A. Socioeconomic determinants of fertility: a cross districts analysis of Punjab, Pakistan. Pakistan J Humanit Soc Sci. 2016;4(2):37-48.

10. Rashad H, Zaky H. A comparative analysis of fertility plateau in Egypt, Syria and Jordan: policy implications. Cairo: Social Research Center, The American University in Cairo: 2013.

11. Rai P, Paudel IS, Ghimire A, Pokharel PK, Rijal R, Niraula SR. Effect of gender preference on fertility: cross-sectional study among women of Tharu community from rural area of eastern region of Nepal. Reprod Health. 2014;11(1):11-15. https://doi. org/10.1186/1742-4755-11-15

12. D'Addato A V, Vignoli D, Yavuz S. Towards smaller family size in Egypt, Morocco and Turkey: overall change over time or socio-economic compositional effect. Popul Rev. 2008;47(2): 21-40.

13. Eyasu AM. Multilevel modeling of determinants of fertility status of married women in Ethiopia. Am J Theor Appl Stat. 2015;4(1):19-25. https://doi.org/10.11648/j.ajtas.20150401.14

14. Zaki H, El-Misery M. Modeling birth intervals in Egypt: a hazard model approach. Paper presented at the 18th Annual Conference on Statistics and Modelling in Human and Social Science, Cairo, Egypt; 2006. 
15. Samari G. Women's status, autonomy and fertility in transitional Egypt [Thesis]. Los Angeles (CA): University of California; 2015.

16. Hailu D, Gulte T. Determinants of short inter-birth interval among reproductive age mothers in Arba Minch District, Ethiopia. Int J Reprod Med. 2016. https://doi.org/10.1155/2016/6072437

17. Bongaarts J. A framework for analyzing the proximate determinants of fertility. Popul Dev Rev. 1978;4(1):105-32.

18. Wickrama KAS, Lorenz FO. Women's status, fertility decline, and women's health in developing countries: direct and indirect influences of social status on health. Rural Sociol. 2002;67(2):255-77. https://doi.org/10.1111/j.1549-0831.2002.tboo103.x

19. Hassneen E, El-Abbasi AH, Khalifa M, Shoaeb F. Using a two-level structural equation model to study the determinants of reproductive behaviour in Giza Governorate. Egypt Inform J. 2019;20(2):143-50.

20. Jain AK, Mahmood A, Sathar ZA, Masood I. Reducing unmet need and unwanted childbearing: evidence from a panel survey in Pakistan. Stud Fam Plann. 2014;45(2):277-99. https://doi.org/10.1111/j.1728-4465.2014.00389.x

21. Metwally A, Saleh R, Abdelhamed A, Salama S, Mores C, Shaaban F, et al. Determinants of unintended pregnancy and its impact on the health of women in some governorates of Upper Egypt. J Arab Soc Med Res. 2015;10(1):1-8.

22. Sultan MK, Bakr I, Ismail N A, Arafa N. Prevalence of unmet contraceptive need among Egyptian women: a community-based study. J Prev Med Hyg. 2010;51(2):62-6.

23. Casterline JB, El-Zanaty F, El-Zeini, LO. Unmet need and unintended fertility: longitudinal evidence from Upper Egypt. Int Fam Plan Perspec. 2003;29(4):158-66. https://doi.org/10.1363/ifpp.29.158.03

24. Tarka P. An overview of structural equation modeling: its beginnings, historical development, usefulness and controversies in the social sciences. Qual Quant. 2018;52(1):313-54. https://doi.org/10.1007/s11135-017-0469-8

25. Arbuckle JL. Amos (version 23.0). Chicago (IL): IBM SPSS; 2014.

26. Durrant GB. Imputation methods for handling item-nonresponse in the social sciences: a methodological review. Swindon: ESRC National Centre for Research Methods and Southampton Statistical Sciences Research Institute; 2005 (NCRM Methods Review Papers NCRM/002).

27. Stata statistical software: release 12. College Station (TX): StataCorp LP; 2011.

28. El-Zanaty F, Hussein EM, Shawky GA, Way AA, Kishor S. Egypt Demographic and Health Survey 1995. Calverton (MD): National Population Council [Egypt] and Macro International Inc.; 1996.

29. Wheaton B, Muthen B, Alwin DF, Summers GF. Assessing reliability and stability in panel models. Sociol Method. 1977;8:84-136. http://dx.doi.org/10.2307/270754

30. Marsh H W, Hocevar D. Application of confirmatory factor analysis to the study of self-concept: First-and higher order factor models and their invariance across groups. Psychol Bull. 1985;97(3):562-82.

31. Tanaka JS, Huba GJ. A fit index for covariance structure models under arbitrary GLS estimation. Brit J Math Stat Psy. 1985;38(2):197-201.

32. Bentler PM, Bonett DG. Significance tests and goodness of fit in the analysis of covariance structures. Psychol Bull. 1980;88(3):588-606.

33. Bentler PM. Comparative fit indexes in structural models. Psychol Bull. 1990;107(2):238-46. https://doi.org/10.1037/00332909.107.2.238

34. Mulaik SA, James LR, Van Alstine J, Bennett N, Lind S, Stilwell CD. Evaluation of goodness-of-fit indices for structural equation models. Psychol Bull. 1989;105(3):430-45.

35. Hu LT, Bentler PM. Cutoff criteria for fit indexes in covariance structure analysis: conventional criteria versus new alternatives. Struct Equ Modeling. 1999;6(1):1-55. 